\title{
IMPROVING THE AVAILABILITY OF MANUFACTURABILITY INFORMATION THROUGH DECENTRALIZATION OF PROCESS PLANNING
}

\author{
Eliab Z. Opiyo \\ Department of Design Engineering; Delft University of Technology \\ Netherlands,e-mail: e.z.opiyo@tudelft.nl
}

\begin{abstract}
Process planning is part of the general product development and production process that usually follows design and precedes manufacturing. Manufacturability and process planning information in general play central role in many product development and production activities, including paradoxically, conceptual and detail design - the activities that take place before process planning. The need of conducting some of the process planning activities formally before or during design is thus rather obvious. One of the main research issues is therefore the identification of the process planning activities that can be performed before the traditional process planning phase and handling of the process planning information so as to adequately provide the designers with the manufacturability information needed during conceptual and detail design. Another issue is how to support collaboration during process planning and how to maintain continuity of the process planning tasks. This paper suggests the decentralization of the process planning task and proposes the execution of the process planning activities in a piecemeal fashion, starting right after receiving an order and specifying the requirements for a product. Process planning under the proposed procedure consists of six semi-autonomous sub-phases, some of which comprise activities that must be conducted prior to the process planning phase. This helps to overcome the problem of timely availability of manufacturability information during the execution of upstream and downstream product development and production activities. The paper also proposes a computer-based method of handling the manufacturability information generated in various stages of the product development and production process. A database design and structure of prototype software that manages the process planning information are presented and discussed. Furthermore, a case study conducted to explore how the proposed process planning procedure could be put in use is presented and discussed.
\end{abstract}

Keywords: Process planning, collaborative process planning, decentralization of process planning, manufacturability.

\section{INTRODUCTION}

The consumer market in general is presently characterized by a continuous change in the market requirements. On the other hand, the manufacturing industry and research and development $(\mathrm{R} \& \mathrm{D})$ organizations are facing never-ending disclosure of new product development and production concepts and methods. These trends are fuelling competition among manufacturing industries. One of the challenges facing the industrial companies is how to meet market requirements for product quality, reduced development and production costs, shorter time-to-market, and product flexibility while improving lead-time and productivity. Overall, the increasing global competition is challenging the manufacturing industry to bring well designed, well manufactured, and competitively priced products to the market in a reasonably short time. Such complex requirements are difficult to fulfill using the traditional product development concepts, methods and tools. While it is true that with the existing concepts, methods and tools the manufacturing organizations have, to a large extent, managed to enhance productivity in many product development and production processes, substantial work is still required to come up with even better concepts, methods and tools. It should, however, be noted that despite the continuous evolution of new concepts, methods and tools, the basic engineering activities have hardly changed in recent years. Only the means of performing the engineering activities, the knowledge needed, the degree of automation in them, and the technologies used have changed radically (Barkmayer, 1996).

There has been a determination to enhance the existing practices; and many researchers in recent years have expressed the need for new concepts, methods and tools for some product development and production activities. For example, Maropolous (1995a) and El Maraghy (1993) suggested that new process planning architectures are required to support the concept of integrated product development and that substantial research is needed to define details of the required functionality, data structures and functional interfaces of tasks within the new process planning architectures. There have been similar thoughts and research by several other research groups (Maropolous, 1995a \& Maropolous, 1995b). Apart from the need of restructuring the way process planning is conducted, a general 
consensus has been forming on the need to revisit the current product development and production process as a whole. There is a strong need to establish better information structures and new relationships and interconnections among activities (Kals, 1997); (Culley et al. 1999) with the ultimate goal of achieving higher flexibility, reducing product development and production costs, shortening time-to-market and promoting greater participation of various stakeholders in the product development and production processes.

This paper describes an attempt aimed at establishing better process planning information structure. It first reviews literature related to the product development and production process, with a focus on process planning; and defines the problem dealt with. It subsequently introduces a new process planning procedure and describes its main elements. It then describes a computer based information storage and retrieval system developed for handling the manufacturability information generated in various stages of the product development and production process. It also presents a case study conducted to explore the potentials and usability of the new modular process planning procedure.

\section{LITERATURE SURVEY AND PROBLEM DEFINITION}

Many researchers recognize the importance of considering concurrently the manufacturability of the eventual product during design (Feng and Song, 2000); (Boothroyd et. al., 1994); (Dixon and Poli, 1995); (Shah and Mäntylä, 1995); (Nederbragt et. al. 1998); (Dewhurst and Boothroyd, 1989), and numerous attempts to come up with appropriate supporting methods and tools have been reported. For example, some researchers have proposed methods for estimation of manufacturing costs in the early stages of the product development and production process (Dewhurst and Boothroyd, 1989); (Ou-Yang and Lin 1997); (Winch, 1989); (Mileham et al., 1993); (Park and Kim, 1995). Others have proposed methods for process selection in the early stages of the product development and production process (Haudrum, 1994); (Giachetti, 1998); (Mukherjee and Liu, 1997). There have also been several research aimed at enabling smooth flow and exchange of information among the product development processes and tools (Kalpakjian, 1995); (Alting, 1994); (Halevi and Weill, 1995); (Wong and Sriram, 1995).

There are numerous related publications on the above-mentioned research topic. These include
(Haudrum, 1994), which describes an approach to consider production methods in design stage, and (Lenau, 1996), which presents a method for the selection of manufacturing processes and materials based on a computer tool that inspires the designer to examine materials and processes. Others include (Giachetti, 1998) which describes prototype material and manufacturing process selection system that integrates a formal, multiattribute decision model with a relational database; (Boothoyd et al. 1994) which introduces a systematic approach to select manufacturing processes according to material and shape; and (Evbuomwan et al. 1995) which describes a design function deployment (DFD) tool to support material and process selection. Furthermore, (Feng and Song, 2000) developed a model as an attempt to initiate the development of standard interface specifications that are necessary for design and process planning integration; and (Korosec et al. 2005) developed a neuro-fuzzy model that uses the concept of "feature manufacturability" to identify and recognize the degree of "pretentiousness - difficulty of machining". In addition, integrated design and process planning is a long standing desire, which, however, is still far from realization. This is largely attributed to the fact that there is no theory or methodology that sufficiently describe the early product development processes such as conceptual design, or a theory that lays down a foundation for integration and proper exchange of information between various product development functions (Ullman, 1997); (Kals, 1997); (Pahl and Beitz, 1996); (Boothroyd et. al., 1994); (Gorti and Sriram, 1996); (El Maraghy, 1993); (Anderl and Mendgen, 1996); (Allada et al., 1997); (Barkmayer, 1996); (Pugh, 1996).

Successful two-way information flow and data exchange between various product development functions and supporting tools is understood to be vital for successful interconnection of activities (Kals, 1997). The problem of availability of formal manufacturability information to, for instance, the upstream activities of feasibility analysis and design is among the research topics dealt with extensively. There have been several pioneering attempts focusing on the idea of conducting the process planning activities in piecemeal. For example, Jasperse (1995) describes process planning in two levels, namely macro process planning and micro-process planning. ElMaraghy (1993) outlines process planning in four levels: generic planning, macro planning, detailed planning, and micro planning. Maropolous (1995 a) and El Maraghy (1993) 
suggested that new process planning architectures are required to support the concept of integrated product development and that substantial research is required to define details of the required functionality, data structures and functional interfaces of tasks within the new process planning architectures. It can be said that although the idea of conducting process planning activities in piecemeal has been talked about for some time, a systematic framework for the execution of process planning activities modularly is not yet available. Reference architecture for modular process planning and a software concept for handling the generated information are therefore needed.

The problems dealt with in this article can therefore be described briefly as follows:

Shows the common sequence of execution of the product development activities. Traditionally, process planning follows design and precedes manufacturing. One of the problems with this practice of execution of the product development activities sequentially is that the manufacturability information needed in various stages of the design process is not formally available when the designers require it. As a result, designers typically prepare their designs based on informal manufacturability information. Another problem is the difficulty of backtracking and establishing how and when the manufacturability decisions were made, and on what manufacturability information a design is based upon. There is a need for executing the process planning activities timely so as to cater for the demands of the manufacturability information in the early phases of the product development and production process. There is also a need of proper management of process planning information and of ensuring that all in-process manufacturability data are stored and kept accessible to various members of the product development team.

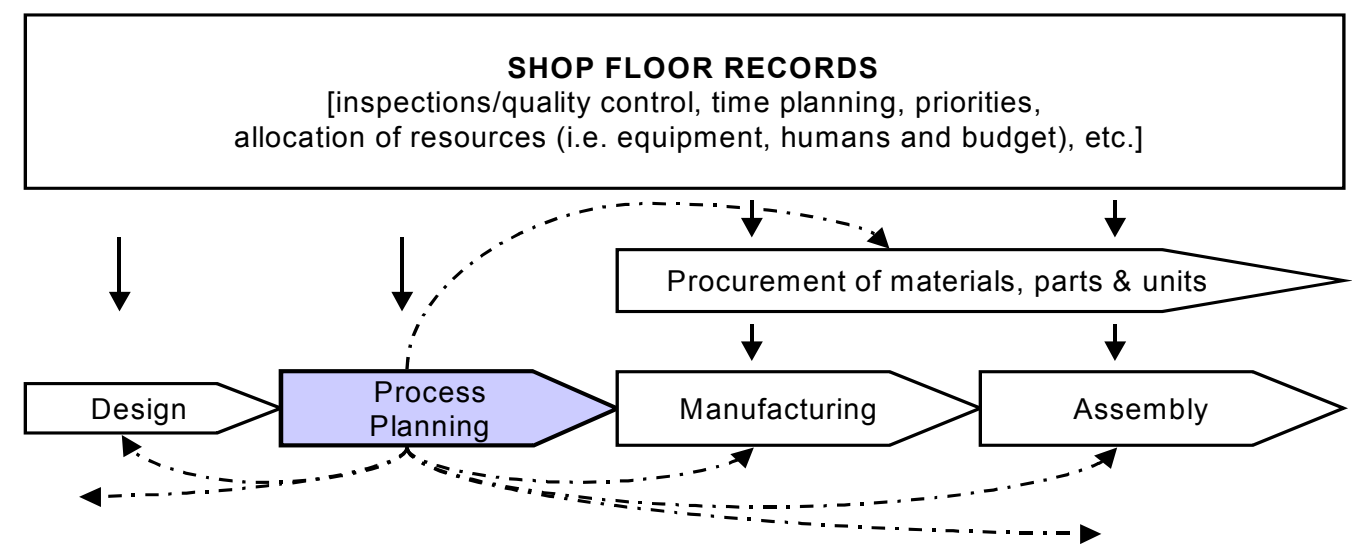

Figure 1: Demand of process planning information in the product development and production process.

Table 1: The main process planning activities

\begin{tabular}{||l||}
\hline \hline Activities \\
\hline Interpretation of the product model \\
\hline Process selection \\
\hline Machining operations selection \\
\hline Machine tool selection \\
\hline Sequencing of operations \\
\hline Tooling selection \\
\hline Design of fixtures \\
\hline Determination of machining variables \\
\hline Determination of machining cost and times \\
\hline Generation of NC programming \\
\hline
\end{tabular}


The research reported in this paper dealt with the above-stated problems, and has resulted into creation of a modular procedure for the execution of process planning activities.

\section{AN OVERVIEW OF THE PROPOSED DECENTRALIZED PROCESS PLANNING PROCEDURE}

Error! Reference source not found. lists the main process planning tasks mentioned in the literature; see for instance; Kiritsis (1995), MacMahon and Browne (1998), Lee (1999), and van Houten (1991). These are the tasks that were referred to when formulating the new modular process planning procedure. Based on empirical study carried out ${ }^{1}$ and on expert judgment ${ }^{2}$, the tasks in Table 1 have been placed in six distinct groups (see Figure 2), mainly by considering how timely each process planning task must be performed to adequately support activities in other product development phases. These six groups of process planning tasks have been dubbed as subphases or modules ${ }^{3}$ of process planning in this article.

This grouping has resulted into fragmentation of the current process planning task, with some activities migrating towards feasibility analysis and design, some remain in the traditional process planning phase, while others have been shifted closer to the machine shop operations, or performed locally at the machine shop. The main advantage of this decentralization is that the global process planning activities can be accomplished collaboratively at the onset of the product development project by a team of decision makers, process planners, production engineers and designers. The conceptual process planning activities on the other hand can be executed in the design phase (that is, based on the conceptual design of the product) by the

1 A study was carried out in some selected product development tasks to explore how activities proceed in actual practice (Opiyo, 1998). The results vindicated that there are considerable infringements and/or overlaps of process planning activities in the entire product development interval.

2 Design decisions strongly influence upstream and downstream product development activities (Pahl and Beitz, 1996), (Tichem, 1997). In this case, the designers who typically choose materials and decide on the appearances of products in a way dictates what should be in the process plan.

3 The term sub phase is used synonymously with the term module in this paper. designers, in collaboration with process planners. Based on the global and conceptual process plans, the process planners can prepare micro process plan, followed by macro process plan, and eventually prepare NC codes.

The two process planning sub-phases, namely: global process planning and conceptual process planning serve the early product development activities such as market survey, conceptual design, and detail design with preliminary, but nevertheless concrete and trustworthy manufacturability information. Each module has definite deliverables and requires specific input information (see Figures 3, 4, 5, 6, 7, and 8). This process planning procedure can be represented by the formal relationship below.

$$
\Lambda=\left\{\lambda_{g l}\right\},\left\{\lambda_{c o}\right\},\left\{\lambda_{m a}\right\},\left\{\lambda_{m i}\right\},\left\{\lambda_{n c}\right\},\left\{\lambda_{f n}\right\}
$$

where; $\left\{\square_{\mathrm{gl}}\right\},\left\{\square_{\mathrm{co}}\right\},\left\{\square_{\mathrm{ma}}\right\}$, and $\left\{\square_{\mathrm{mi}}\right\}$, stands for sets of global, conceptual, macro, and micro process planning activities. $\left\{\square_{\mathrm{nc}}\right\}$ stands for NC programming, while $\left\{\square_{\mathrm{fn}}\right\}$ stands for fine-tuning and certification of the process planning document (see Error! Reference source not found.).

For an organization working according to the proposed modular process planning procedure, the process planning department has the overall obligation of supervision and coordination of the process planning activities, of administering the flow of manufacturability information among different departments and phases of the product development and production process, as well as of compilation of the final process planning document. The following sub sections give detailed descriptions of the proposed modules of process planning. 


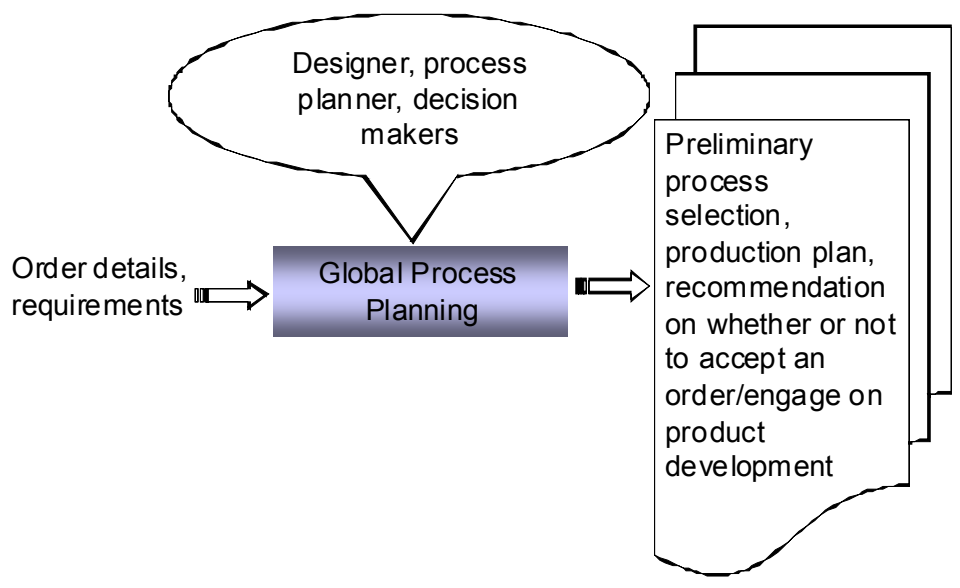

Figure 3: Global process planning

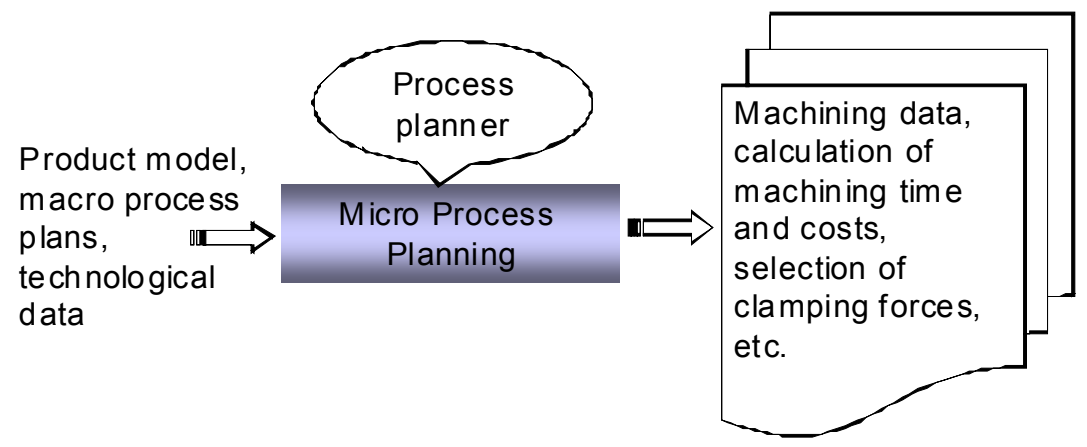

Figure 6: Micro process planning

\subsection{Global Process Planning, $\square \mathrm{gl}$}

Global process planning (Opiyo, 1998) comprises a set of process planning activities that generate the manufacturability information required in the very early stages of the product development process, for instance during market study or feasibility analysis (Figure 3). Global process plans are prepared collaboratively by a team of designers, process planners and decision makers (including, for instance the production managers and marketing managers). It is intended to provide formal manufacturability information early on to the decision-makers in order to support them in making decisions on, for instance, whether or not to accept the order.

\section{The input information}

Into this process planning sub-phase are the details of the order (including order quantity, delivery time and procedural conditions), customer's definition of the product and requirements, and the initial ideas of the designer. The output of global process planning are the specifications on the type(s) of manufacturing process (es) and the operations needed in the production of the final product, as well as the global production plan. The decision to accept or reject an order can be made partly based on the global process plans. 


\section{Conceptual Process Planning}

Conceptual process planning, see (Feng and Song, 2000; Opiyo, 2004) is an activity for the designers to evaluate manufacturability of the product, and to determine manufacturing cost in the early stages of the design process. It is intended to ensure that manufacturability constraints are taken into the consideration during conceptual and detail design (Figure 4). The process planning activities performed in this sub-phase includes: selection of processes and machine tool(s) and preliminary identification of tooling and fixtures.

The conceptual process planning activities are performed collaboratively by the designers and the process planners, and are based on the requirements for product, as well as on the conceptual design of the product. Due consideration is also given to the manufacturing resources information (that is, information about machine tool(s), tooling, and fixtures within the company or outside the company, and accessible to the company) when preparing conceptual process plans. Typical input parameters into the conceptual process planning process include preliminary information on, for instance, shape of the intended product (in the form of sketches or design drafts); required surface roughness, and tolerances; materials information; and details of the order (that is delivery time, batch size, and procedural conditions).

\section{Macro Process Planning, $\square$ ma}

Macro process planning (Jasperse, 1995; El Maraghy, 1993) deals with set-up planning (Figure 5). It also involves endorsing the conceptual and global process plans. This implies re-running the global and conceptual process planning activities, namely selection of: (i) process, (ii) machine tool(s), (iii) fixture(s), and (iv) tool(s); to re-check the correctness of the results. The inputs to this process planning subphase include the product model, preliminary (that is, global and conceptual) process plans, and manufacturing resources data. The process planners prepare macro-process plans by taking into the consideration also other requirements, including delivery time and order quantity.

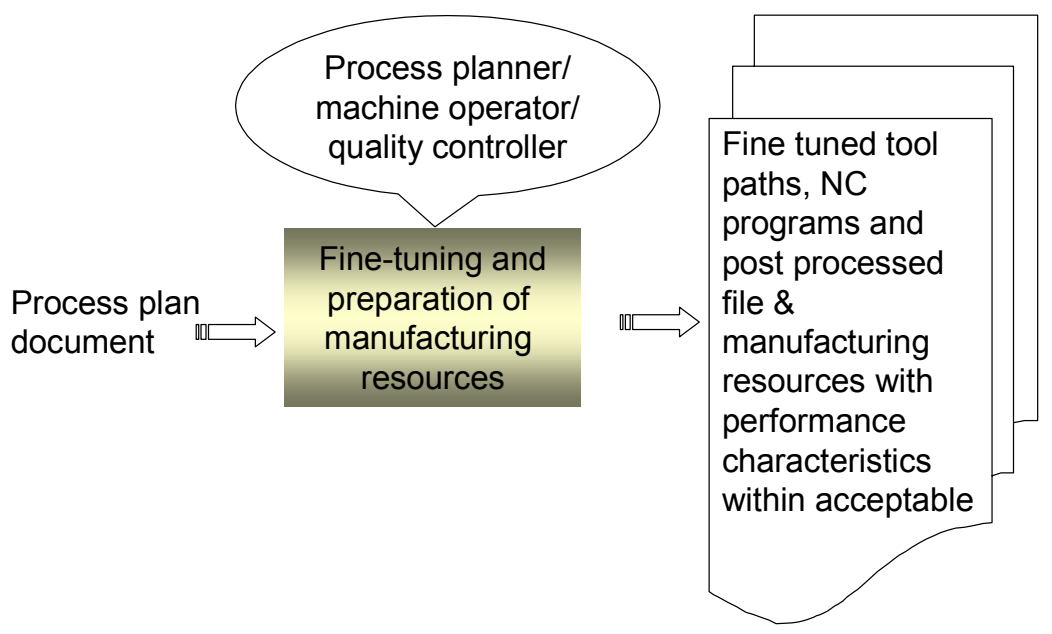

Figure 8: Fine-tuning and preparation of manufacturing resources 
Micro Process Planning, $\square_{\mathrm{mi}}$

Micro process planning (Jasperse, 1995; El Maraghy, 1993) involves determination of machining conditions (that is, cutting speeds, depths of cut and feed rates), and calculation of machining time (Figure 6). The inputs to this subphase include the product model and the outputs of the macro process planning process (for instance, selected processes, machine tools and tools). Micro process plans are prepared by the process planners, who typically pay attention to the underlying manufacturing technologies and theories such as tooling technology and theories of metal cutting or metal forming.NC

\subsection{Programming, $\square_{\mathrm{nc}}$}

The main task in the NC programming (see for instance Lee, 1999) sub-phase is generation of

\subsection{Fine-tuning and Certification of Manufacturing Resources, $\square_{\text {fn }}$}

Fine-tuning and certification of process plans is the final set of activities under the proposed modular procedure for the execution of process planning activities (Figure 8). Fine-tuning must be conducted by a team of experienced process planners and/or machine operators to re-check and see if the process plan document is correct. The certification process involves re-checking the selected equipment (i.e. machine tools, tools and fixtures) to establish their 'fitness' and their tool paths and inclusion of machining conditions in the part program (Figure 7). Software utilities available on the traditional CAD/CAM systems are typically used to automatically generate tool paths and NC programs. The process planners have the obligation of verifying the generated tool paths and NC programs. The product model and machinability data are the main input information needed in the process of generation of tool paths and NC programs. The simulation utilities available on CAD/CAM systems are typically used to simulate movements of the tools along the tool paths to check, for instance, for collisions and correctness of the tool path. The output of this process planning sub-phase is a verified NC program.

have been decentralized and distributed throughout the product development and production process, including in the early product development phases.

\section{Computer support of a decentralized process planning}

This section describes the modular - process planning (M-PP) software, which comprises several software tools, including a web-based information storage and retrieval utility that provide manufacturability information to the designers and to other experts involved in the

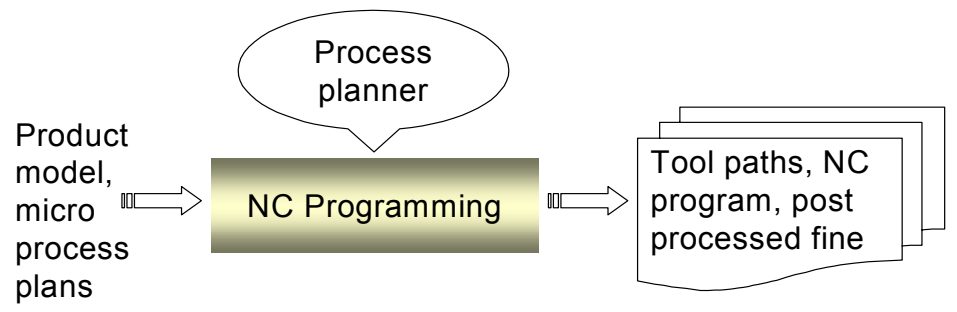

Figure 7: NC programming

availability for manufacturing. The 'fitness checking' of the machine tools may include: performing acceptance tests in order to examine if the machine tool(s) in question can produce parts within the specified accuracy limits. Quality control departments should also be involved in the fine-tuning process. The output of this process planning sub-phase is a verified process plan document.

Figure 9 shows functional interfaces of the proposed process planning sub-phases in the product development and production process. As it can be seen, the process planning activities product development and production process. Data generated from the process planning activities discussed in the previous section are stored in a server that is accessible to various members of the product development team via the web. Thus, the discussion also focuses on how the necessary data items of the M-PP database were identified, and on the design of the database.

\subsection{Database Contents and Design}

The approach used to set up the contents of the database is presented first. To specify what 


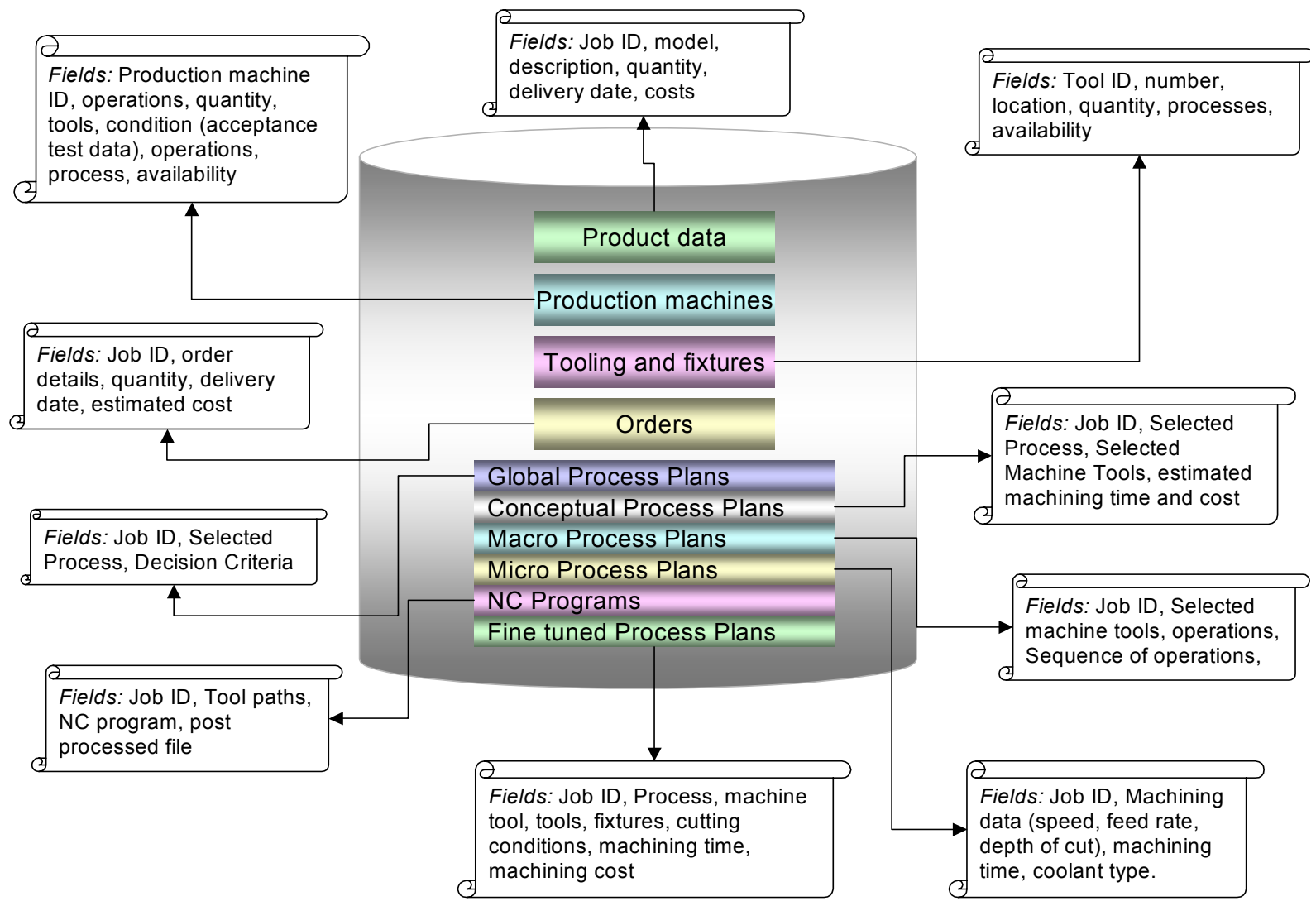

Figure 10: Contents of the database of the M-PP software

should be in the database, the process planning information required for the execution of product development and production activities, as well as various kinds of information required for preparation of process plans were identified. This involved the following:

- Studying documents (such as tooling catalogues and machine tool manuals) used in various product development and production processes.

- From various publications, the technological data frequently required in various product development and production activities such as the materials data and tooling data were identified.

- Investigation of what is actually happening in practice. The conventional non-computerized methods applied in the design and shop floors departments for managing the product data or the manufacturing resources data such as index cards and other paper based methods were studied to see how they could be incorporated in the design of the database. Also, information required in the product development and production process such as information about previous designs, orders, suppliers and customers were identified and adapted for incorporation in the database.

- Adopting features of the existing information systems. The information systems e.g. databases presently used in the product development and production processes were studied and some of their design features included in the design of the MPP software's database.The information items were then structured as shown in Figure 10. A prototype M-PP software was subsequently implemented. It uses the mySQL database technology ${ }^{4}$. In the prototype M-PP software, $\mathrm{SQL}^{5}$ commands can be executed from the HTML and PHP $^{6}$ based graphical user interfaces.

\footnotetext{
${ }^{4}$ mySQL database server is one of the most popular open source database.

${ }^{5}$ The mySQL query language is the Structured Query Language (SQL).

${ }^{6} \mathrm{PHP}$ is a server-side script language, i.e. script is run on the web server, not on the user's browser. It stands for Hypertext Preprocessor.
} 


\subsection{Why Computerization?}

The M-PP database provides a computerized environment for organization and management of the manufacturability information generated when following the proposed modular process planning procedure. It serves two broad roles, namely: (i) it provides manufacturing resources information, namely, the information about machine tools, fixtures and tooling; and (ii) it avails the design-related manufacturability information to both downstream and upstream product development activities. The goal is to sufficiently meet the manufacturability information needs in the product development and production process, and to support collaboration among various departments involved. In accomplishing the role of providing the manufacturability information to the upstream and downstream product development activities, the information is made available to the developers via the web. This tool: (a) improves the availability of the manufacturability information; (b) enables the design team to quickly explore the capability of the manufacturing organization or machine shop to produce the designed product; (c) facilitates collaboration among various departments that take part in process planning, and (d) supports and promotes reuse of product information. Other benefits include:

- Better coordination of the process planning activities.

- Facilitates tracking of the progress of the process planning task in various phases of the product development and production process. For instance, it provides a way to backtrack to the previous process planning sub-phases.

- Storing process plans and providing the process plans in various formats, for instance, as plain text or as HTML text.

- $\quad$ Providing sorted information for various activities in the product development and production process. For instance, the designers can be supplied with the manufacturability information required for design purposes while the manufacturing department can be provided with the information needed in manufacturing.

The M-PP software can be used, first, in decision making, for instance, on whether or not to accept an order; and secondly, for supporting the designers during design and the process planners when compiling the process planning document. For the former application, it equips the decision makers (including even the management of the company) with software tools that help them to visualize and predict, for instance, the possibility of whether or not the order can be manufactured according to the specifications and delivered in time; based on formal manufacturability information. In the later application scenario, the M-PP software provides the designers with the capability to anticipate and consider the manufacturability constraints and requirements while for the process planners, it equips them with the capability to backtrack and discovering, for instance, on what manufacturability data the design is based.

The outputs of the M-PP software tool are numerous and depend primarily on search criteria. By specifying appropriate keywords as search criteria, a process plan document for a given product which include selected processes; operations; manufacturing resources such as machine tool(s), fixture(s) and tool(s); sequence of operations; machining conditions; machining time and costs; and NC program can be retrieved. Similarly, the process plans that correspond to various sub-phases can be retrieved by specifying proper keywords as search criteria. Having a simple user interface, the M-PP software is in particular useful to the conceptual and detail design processes in view of the fact that it brings into the design process both the manufacturing technology knowledge and machine shop information. Consequently, the design of the product can be finalized and evaluated based on formal manufacturability information, but obviously by taking into the consideration other design aspects such as functionality, aesthetics and ergonomics as well. This reduces the possibility of having needless iterations between design and subsequent or preceding activities.

\section{APPLICATION CASE STUDY}

This section recounts and compares two product development and production processes, namely: one that was conducted by closely following the traditional product development practice in which process planning follows design, and another one that embraced the collaborative modular process planning philosophy, in which the process planning activities were executed according to the scheme illustrated in Figure 9. This study took place at a medium scale product development enterprise (referred to in this paper 
simply as Company $\mathrm{R}^{7}$ ) equipped with a few manufacturing resources with modest capabilities. The case study was on the design and manufacture of a gearbox of a draw bench test rig. The customer of this gearbox was $R \& D$ organization, which needed a draw-bench test rig for research purposes. Two graduate mechanical engineers were assigned to undertake the design task and to take part in manufacturing, as part of on job training assignments. One engineer (referred to hereafter as "Designer X") was asked to strictly follow the traditional product development approach $^{8}$ of first conducting feasibility study and needs analysis, followed by preparing specifications, designing, process planning and manufacturing. Another graduate mechanical engineer (referred to hereafter as "Designer Y") was requested to follow the new process planning procedure (that is, to closely follow the scheme illustrated in Figure 9) and was supported with the M-PP software. One supervisor (referred to hereafter as "project leader") supervised the two designers. Apart from the requirements and a consensus on the basic structure and main components and units of the gearbox, the following constraints were also made known to the two designers in advance, namely: (i) all components were to be manufactured at the Company R's machine shop, and (ii) no job outsourcing was to be allowed. The designers were allowed to discuss their design proposals with the machine shop experts ${ }^{9}$.

Designer $\mathrm{X}$ designed the above-mentioned gearbox by closely following the traditional product development approach of first conducting feasibility study and carrying out needs analysis, followed by preparation of specification requirements, design, process planning, and manufacturing. This designer maintained regular contact with the project leader, who was also an engineer responsible for supervision of the design

7 The name and the address of the company are intentionally not revealed.

8 The traditional product development approach typically entails linear execution of the product development of activities, that is: execution of feasibility and needs analysis, requirements specification, design, process planning, manufacturing and testing sequentially, see for instance (Pahl and Beitz, 1996); (Roozenburg and Eekels, 1995); (Tichem, 1997) and (Blessing, 1994).

9 Consultations were restricted only as permitted by respective product development frameworks, that is, traditional approach - for Designer X, and the framework illustrated in Figure 9 - for Designer Y. activities in Company R. In the end, the Designer $\mathrm{X}$ prepared the final drawings under close supervision of the project leader, and submitted them to the shop floor for manufacturing and assembly. Figure 12 (a) and Table 2 in the appendix describe the Designer $X$ 's design proposal. It became evident after thorough scrutinies in the shop floor that one of the major components of the gearbox, namely, the wheel; could not be manufactured by using the available manufacturing resources. According to the design, the outside diameter of the wheel was 415 $\mathrm{mm}$ while both the universal milling machine and the lathe machine available in the machine shop had the capability of handling up $400 \mathrm{~mm}$ diameter only. These manufacturability constraints were not known to the designer in advance, and were therefore not taken into the consideration during design.

Designer $\mathrm{Y}$ was also assigned the same task of designing the gearbox of a draw bench test rig. This designer closely followed the new computer-based modular process planning procedure. Designer $\mathrm{Y}$ worked on the design concepts while constantly keeping an eye on the manufacturability data stored in the M-PP software's database ${ }^{10}$, and at the same time maintained regular contact with the shop floor experts. In addition, regular meetings between the stakeholders involved in the product development and production process, namely, the Designer Y, the project leader, the production engineer and the machine operators were frequently held to discuss various issues related to the development of the gearbox. These 'task meetings' started as early as from the inception of the project. The discussions in these meetings centered on issues such as the merits and demerits of alternative design concepts, functionality of the design, completeness of the design, and manufacturability of the design. In particular, the concepts related to various aspects of the gearbox design were scrutinized to foresee their implications, and also the product development team studied the design thoroughly to determine if various components (i.e. shafts, gears, bearing housings and housing parts) could be manufactured and if the tolerances and surface quality specifications were attainable by using the

\footnotetext{
${ }^{10}$ Key product development data, including the manufacturing resources data such as capabilities of the machine tools, tools stock, tools location and tool availability (see Figure 10) were stored in the MPP software's database.
} 
available machine tools and tooling. This was only possible due to the availability of reliable manufacturability information, which was achieved by using the M-PP software and by incorporation of panelists with different backgrounds and skills, including manufacturing, in the discussion panels. The steps that the Designer $\mathrm{Y}$ followed are summarized in Figure 11.

In Step 1 and Step 3, both the M-PP software database and the machine shop experts served as the source of manufacturability information for the Designer Y. This designer frequently turned to the machine shop experts for advice whenever there was a need of manufacturability information, namely, the need of information about, for instance, the capacities and availability of machine tools, tooling and fixtures needed in the preparation of process plans. Inputs from the machine shop experts were also sought on a regular basis through formal and informal discussions. Figure 12 (b) and Table 3 in the appendix describe the Designer Y's alternative design. Compared with the design prepared by the Designer $\mathrm{X}$, all components in the Designer Y's alternative design could be manufactured in the Company's machine shop.

\section{DISCUSSION}

As mentioned earlier, the primary objective of this research was to develop a generic process planning

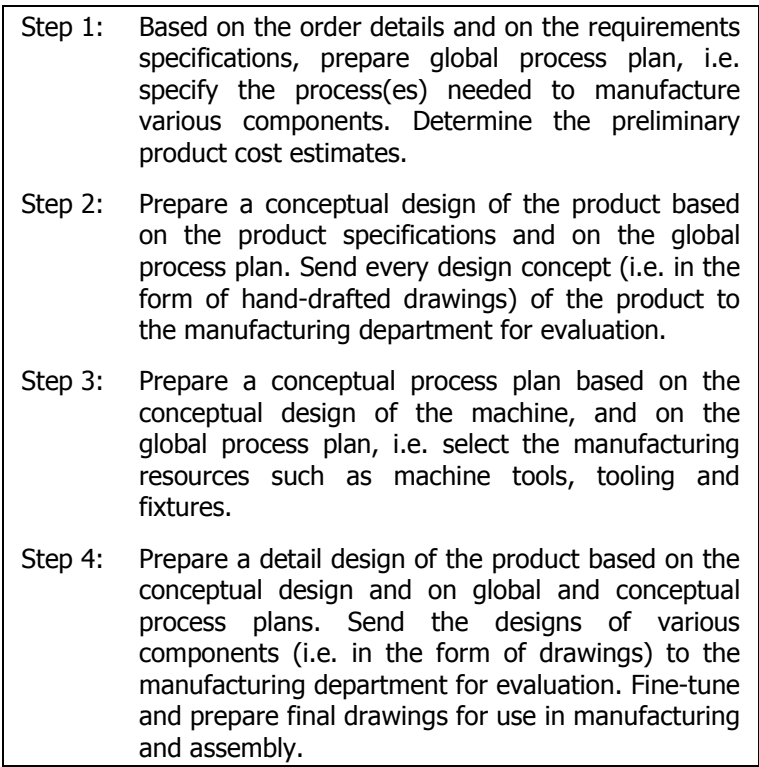

Figure 11: Steps for preparing process plan under the proposed modular process planning procedure procedure that would appropriately back the product development and production process. The focus was on creation of a procedure that would furnish the early product development activities of feasibility analysis, conceptual design, and detail design with formal manufacturability information. The specific aims were to reduce the need to perform various product development tasks recursively, to promote collaboration among experts with different professional backgrounds in a manufacturing organization, and to involve humans as primary source of information for the product development activities.

A decentralized and modular process planning procedure and software have been developed as a result, and applied to solve an industrial application problem. The new procedure embraces some elements of pioneering ideas on decentralization of process planning suggested by ElMaraghy (1993), Maropolous (1995a \& b) and Jasperse (1995). The new procedure and software have been found to be useful in the product development and production process, with the M-PP software in particular quite helpful in managing the information generated in various sub-phases of process planning. It furnished the Designer $\mathrm{Y}$ with formal manufacturability information, that is, it kept the Designer $\mathrm{Y}$ constantly aware of the manufacturing constraints and capabilities of various manufacturing resources in the shop floor. This enabled this designer to finetune the design to match the capabilities of the available manufacturing resources. It can be said that the availability of manufacturing technology and machine shop information (enabled by the M-PP software) allowed this designer to carry out accurate manufacturability analyses early on. By using this tool, it was also possible for this designer, for instance, to plan the manufacturing resource requirements in advance, based on the requirements for the product and on the initial ideas about the product.

There are many possible benefits of following the proposed decentralized process planning procedure. The information generated during global and conceptual process planning is useful during decision-making, for instance, in deciding on whether or not to accept an order. The early process planning sub-phases have in particular been created to enable the designers reliably assess the manufacturability of design proposals early on. The availability of formal manufacturability information is important in the early stages of the product development and production process because it can avoid or reduce iterations in the early processes. The application case study has shown that the modular 
process planning procedure reduces feedback loops in the design process. In this case, the Designer Y, supported with the M-PP software, used the global and conceptual manufacturability information and took into the consideration manufacturability constraints of the design early on. This helped to avoid feedback loops that could have been caused by lack of formal manufacturability information. Also, the modular process planning procedure allows flexibility in the execution of process planning activities. For example, in the proposed modular process planning procedure, some of the process planning activities have been shifted closer to manufacturing (i.e. to the machine shops). This allows more autonomy for the designers, process planners, and machine operators ${ }^{11}$. In addition, the modular process planning procedure facilitates portability of process planning knowledge among various departments of the manufacturing organization and promotes collaboration among the designers, process planners, machine operators and the management in preparation of process plans.

The use of computers in managing the manufacturability information generated by different experts in various departments of the organization is central to the success of the modular process planning procedure. Computers bring in the power to store, communicate and process the information generated in different time scale and by different experts or departments. Compared with computer support, manual methods are generally tedious and there is also always the danger of losing valuable information, especially if the product development and production process extends over a long period of time.

In general terms, the proposed decentralized process planning procedure brings flexibility into the process planning process, formalize and enhance collaboration among various members of the product development team, and provide stakeholders in the product development and production process with explicit manufacturability information at the right time. These should reduce the number of iterations in the product development and production process caused by lack of formal manufacturability information, and should also contribute towards

\footnotetext{
${ }^{11}$ It should be noted in this respect that with modern machining centers and $\mathrm{CNC}$ machines (which have sophisticated controllers, powerful CPU, and higher programming capability), NC programming could also be performed even at the machine tool by an experienced machine tool operator.
}

good solutions. Studies show that timely availability of information in the design process contributes toward good solutions; see for instance (Pahl et al., 1999), (Feng and Song, 2000).

\section{CONCLUSION}

The research reported in this paper aimed at developing a process planning procedure that corresponds to the information needs of the product development and production process, including the needs of the early product development activities of conceptual and detail design. This was an attempt to resolve the paradox that design is traditionally based on informal manufacturability information. The development of this procedure involved, among other things, defining the key features of the anticipated procedure, including data structures, flows of information, and functional interfaces of tasks. A phased process planning procedure has been proposed as a result, and the position and role of process planning in the product development and production process has slightly been redefined. According to this procedure, process planning extends incrementally over the entire product development and production process. It attempts to answer questions such as when a particular process planning activity should be executed to appropriately support the product development and production process. Its overall goal is to avoid the costly and timeconsuming iterations caused by the lack of formal manufacturability information during design, as well as in other early product development activities. Prototype software that manages the manufacturability information generated when working according to the proposed procedure has also been designed and implemented. The new process planning procedure has been applied to solve an industrial design problem. It enabled a designer to design a product based on formal manufacturability information. This avoided the iterations that could have been caused by the lack of formal manufacturability information during design. Despite the achievements described in this paper, further research is still needed. For example, the new modular process planning procedure still needs to be tested further in industrial environments to explore its potentials and usability. 


\section{REFERENCES}

Allada, V. Feng S., and Ray, S., (1997) "Development of a Message Model to Support Integrated Design and Manufacturing," Advances in Industrial Engineering Applications and Practice II, pp. 867-872.

Alting, L., (1994). Manufacturing Engineering Processes, Marcel Dekker, Inc.

Anderl R., and Mendgen, R. (1996). "Modeling with constraints: theoretical foundation and application," Computer-Aided Design, Vol.28, No.3, pp.155-168.

Barkmeyer E. J., (editor), (1996). SIMA Reference Architecture Part 1: Activity Models, The National Institute of Standards and Technology Internal Report 5939, Gaithersburg, Maryland.

Blessing, L. T. M., (1994). A Process-Based Approach to Computer-Supported Engineering Design, Ph.D. Thesis, University of Twente, Enschede, Netherlands.

Boothroyd, G., and Dewhurst P, W. (1994). Knight, Product Design for Manufacture and Assembly, Marcel Dekker, Inc.

Culley, S. J., Boston, O. P., and McMahon, C. A., (1999), "Suppliers in New Product Development: Their Information and Integration", Journal of Engineering Design, Vol. 10 No. 1 pp. 59-75.

Dewhurst P., and Boothroyd, G., (1989). "Early Cost Estimating in Product Design," Journal of Manufacturing System, Vol.7, No.3, pp. 183-191.

Dixon J. R., and Poli, C., (1995) Engineering Design and Design for Manufacturing - A Structured Approach, Field Stone Publishers, Conway, Massachusetts.

El Maraghy, H. A., (1993), "Evolution and Future Perspectives of CAPP", Annals of the CIRP, Vol. 42 No. 2, pp. 739 - 751.

Evbuomwan N. F. O., Sivaloganathan S., and Jebb A., (1995). "Concurrent materials and manufacturing process selection in design function deployment," Concurrent Engineering: Research \& Applications (Vol.3, No.2, 1995), pp. 135-143

Feng S C.; and Song E. Y., (2000), "Information Modeling of Conceptual Process Planning Integrated with Conceptual Design", Proceedings of the DECT 2000, $5^{\text {th }}$ Design
For Manufacturing Conference, Baltimore, Maryland Paper No DECT2000/DFM-14009.

Giachetti, R. E., (1998). "A Decision Support System for Material and Manufacturing Process Selection," Journal of Intelligent Manufacturing, Vol. 9, No. 3, pp. 265-276.

Gorti S. R., and Sriram, R. D., (1996). "From Symbol to Form: A Framework for Conceptual Design," Computer-Aided Design, Vol.28, No.11, pp. 853-870.

Halevi G., and Weill, R. D., (1995). Principles of Process Planning - A logical approach, Chapman \& Hall, Inc.

Haudrum, J., (1994). Creating the Basis for Process Selection in the Design Stage, Ph.D. dissertation, the Institute of Manufacturing Engineering, Technical University, Denmark.

Houten, F.J.A.M van., (1991), "PART - A Computer Aided Process Planning System" Ph.D. Thesis, University of Twente, Enscade, Netherlands.

Jasperse, H. B., (1995). "A Macro Process Planning System for Machining Operations" Ph.D. Thesis, TU Delft.

Kalpakjian, S., (1995). Manufacturing Engineering and Technology, $3^{\text {rd }}$ Edition, Addison-Wesley Publishing Company.

Kals, H. J. J., (1997), "Manufacturing Systems Integration by Information Management", A Paper Presented at the Korean Institute of Science and Technology (KIST), Seoul, South Korea.

Kiritsis, D., (1995), “A Review of Knowledge Based Expert Systems for Process Planning: Methods and Problems", International Journal of Advanced Manufacturing Technology, Vol. 10 No. 5, pp. 240-259.

Korosec, M., Balic J., and Kopac J., (2005). "Neural network based manufacturability evaluation of free form machining", International Journal of Machine Tools and Manufacture, Vol. 45, Issue 1, 2005, pp. 1320.

Lee, K., (1999), "Principles of CAD/CAM/CAE Systems", Addison-Wesley.

Lenau T., (1996). "The Missing Element in Design for Manufacture," The Annals of the CIRP, Vol. 45, No.1, pp. 105-108. 
MacMahon, C., and Browne, J., (1998), "CAD/CAM: Principles, Practice and Manufacturing Management", AddisonWesley.

Maropolous, P. G., (1995a), "Review of Research in Tooling Technology and Process Planning - Part I: Process Planning”, Computer Integrated Manufacturing Journal, Vol. 8, No. 1, pp. 13-20.

Maropolous, P. G., (1995b), "Review of Research in Tooling Technology and Process Planning - Part II: Tooling and Process Modeling", Computer Integrated Manufacturing Journal, Vol. 8, No. 1, pp. 512.

Mileham A. R., Currie G.C., Miles A.W., and Bradford D.T., (1993). "A Parametric Approach to Cost Estimating at Conceptual Stage of Design," Journal of Engineering Design, Vol.4, No.2, pp. 117-125.

Mukherjee, A., and Liu, C.R. (1997). "Conceptual Design, Manufacturability Evaluation and Preliminary Process Planning Using Function-Form Relationships in Stamped Material Parts," Robotics \& Computer Integrated Manufacturing, Vol.13, No.3, pp. 253-270.

Nederbragt W., Allen R., Feng S.' Kaing S., Sriram, S., and Zhang Y., (1998). "The NIST Design/Process Planning Integration Project," the Proceedings of AI and Manufacturing Research Planning Workshop, Albuquerque, New Mexico, August, pp. 135139.

Opiyo, E. Z., (2004). "Review of the Product Development Process and Information Flow in the Manufacturing Industry: Problems and a Possible Way Forward", Uhandisi Journal Vol. 27 No. 1, pp. 1-16.

Opiyo, E. Z., (1998), "Development of a Hybrid System for Product Development and Production - With a new Process Planning Procedure", Research Report, Vakgroep Ontwerp en Productie, Delft University of Technology, pp. 1-118.
Ou-Yang C., and Lin, T. S., (1997). "Developing an Integrated Framework for Feature-based Early Manufacturing Cost Estimation," International Journal of Advanced Manufacturing Technology, Vol. 13, pp. 618-629.

Pahl, G., Badke-Schaub, P., and Frankenberger, E., (1999), "Resume of 12 Years Inter-Disciplinary Empirical Studies of Engineering Design in Germany" Design Studies, Vol. 20 No. 5, pp. 481-494.

Pahl, G., and Beitz, W., (1996), "Engineering Design - A Systematic Approach”, Springer Verlag London Limited.

Park C. S., and Kim G. T., (1995). "An economic evaluation model for advanced manufacturing systems using activity-based costing", Journal of Manufacturing Systems, Vol.14, No.6, pp. 451-439.

Pugh S., (1996). Creative Innovative Products Using Total Design, Addison-Wesley Publishing Company, Inc.

Roozenburg, N. F. M., and Eekels, T., (1995). Product Design: Fundamentals and Methods, John Wiley \& Sons.

Shah, J. J., and Mäntylä, M., (1995). Parametric and Feature-based CAD/CAM, John Wiley \& Sons, New York.

Tichem, M., (1997). "A Design Coordination Approach to Design for X", Ph.D. Thesis, Delft University of Technology, Delft, Netherlands.

Ullman, (1997). The Mechanical Design Process, $2^{\text {nd }}$ Edition, McGraw Hill Companies, Inc.

Winch, W., (1989). Realistic Cost Estimating for Manufacturing, $2^{\text {nd }}$ Edition, published by the Society of Manufacturing Engineers.

Wong A., and Sriram, D., (1995). "SHARED: An Information Model for Cooperative Product Development," Research in Engineering Design, Vol.5, pp. 21-39. 
Appendix 1: Illustrations

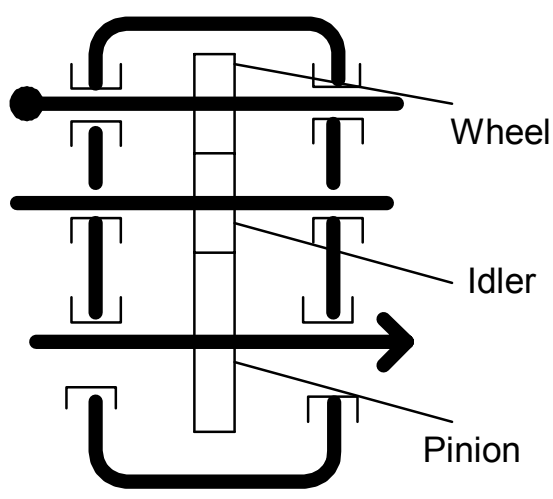

(a)

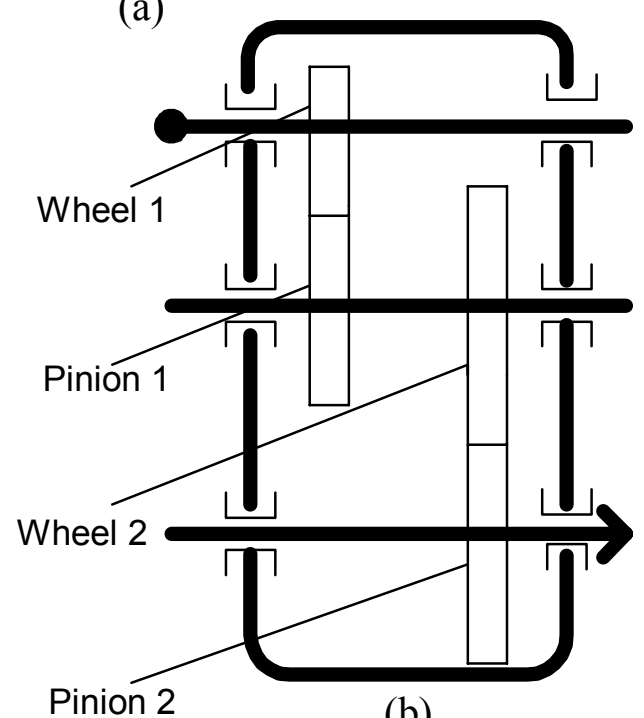

(b)

Figure 12: Schematic diagrams of gearbox designs: (a) Layout of a gearbox designed by following the traditional approach; (b) Layout of a gearbox designed by following the modular process planning procedure. 
Table 2: Designer X's final design

Description: One set of Wheel and Pinion; Material 60WCr7 Steel. Key Manufacturing Resources: Universal Milling Machine: - Work Volume: xyz $=500 \mathrm{~mm}$ x $400 \mathrm{~mm}$ x $400 \mathrm{~mm}$; - Speed range: 45 - $2000 \mathrm{rpm}$; Universal Lathe Machine: - Swing: 400 mm; - Bed Length (i.e. center to center distance): $1200 \mathrm{~mm}$; -Speed Range: $19-2000 \mathrm{rpm}$.

\begin{tabular}{|c|c|c|c|}
\hline Part & No. & Dimension [mm] & Remarks \\
\hline Wheel & 1 & $\begin{array}{l}\text { PCD. } 415.4 \times 45 ; m=6 ; \\
\square=15^{\circ}\end{array}$ & $\begin{array}{l}\text { PCD is } 415 \mathrm{~mm} \text {. This could not be machined } \\
\text { on a universal milling machine or on the lathe } \\
\text { machine. }\end{array}$ \\
\hline Pinion & 1 & $\begin{array}{l}\text { PCD. } 102 \times 45 ; m=6 ; \\
=10^{\circ}\end{array}$ & $\begin{array}{l}\text { PCD is } 102 \mathrm{~mm} \text {. This could be machined on a } \\
\text { universal milling machine or on a lathe } \\
\text { machine. }\end{array}$ \\
\hline Idler & 1 & $\begin{array}{l}\text { PCD. } 102 \times 45 ; m=6 ; \\
=10^{\circ}\end{array}$ & $\begin{array}{l}\text { PCD is } 102 \mathrm{~mm} \text {. This could be machined on a } \\
\text { universal milling machine or on a lathe } \\
\text { machine. }\end{array}$ \\
\hline Top Cover & 1 & $675 \times 140 \times 10$ & $\begin{array}{l}\text { Could be manufactured by using the available } \\
\text { manufacturing resources }\end{array}$ \\
\hline \multicolumn{4}{|c|}{ 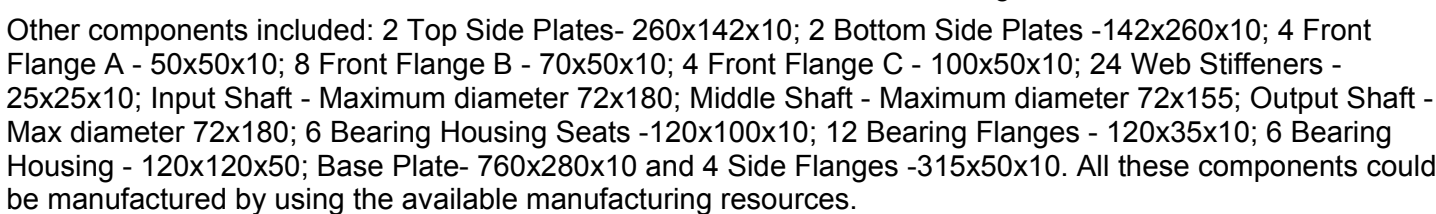 } \\
\hline
\end{tabular}

Table 3: Designer Y final design

Description: Two sets of Wheel and Pinion; Material Ck45 Steel. Key Manufacturing Resources: Universal Milling Machine: - Work Volume: xyz = $500 \mathrm{~mm}$ x $400 \mathrm{~mm}$ x $400 \mathrm{~mm}$; - Speed range: 45 - $2000 \mathrm{rpm}$; Universal Lathe Machine: - Swing: 400 mm; - Bed Length (i.e. center to center distance): 1200 mm; -Speed Range: 19 - 2000 rpm.

\begin{tabular}{|c|c|c|c|}
\hline Part & No. & Dimension [mm] & Remarks \\
\hline Wheel 1 & 1 & $\begin{array}{l}\text { PCD. 281.5x56; } m=6 ; \square= \\
15^{\circ}\end{array}$ & $\begin{array}{l}\mathrm{PCD} \text { is } 293.5 \mathrm{~mm} \text {. This could be machined on a } \\
\text { universal milling machine and on a lathe machine. }\end{array}$ \\
\hline Wheel 2 & 1 & $\begin{array}{l}\text { PCD. 281.5x56; } m=6 ; \square= \\
15^{\circ}\end{array}$ & $\begin{array}{l}\text { PCD is } 293.5 \mathrm{~mm} \text {. This could be machined on a } \\
\text { universal milling machine and on a lathe machine. }\end{array}$ \\
\hline Pinion 1 & 1 & $\begin{array}{l}\text { PCD. } 138 \times 56 ; m=6 ; \\
15^{\circ}\end{array}$ & $\begin{array}{l}\mathrm{PCD} \text { is } 138 \mathrm{~mm} \text {. Could be manufactured by using } \\
\text { the available manufacturing resources }\end{array}$ \\
\hline Pinion 2 & 1 & $\begin{array}{l}\text { PCD. 138x56; } m=6 ; \square= \\
15^{\circ}\end{array}$ & $\begin{array}{l}\text { PCD is } 138 \text {. Could be manufactured by using the } \\
\text { available manufacturing resources }\end{array}$ \\
\hline Top Cover & 1 & $700 \times 225 \times 10$ & $\begin{array}{l}\text { Could be manufactured by using the available } \\
\text { manufacturing resources }\end{array}$ \\
\hline \multicolumn{4}{|c|}{ 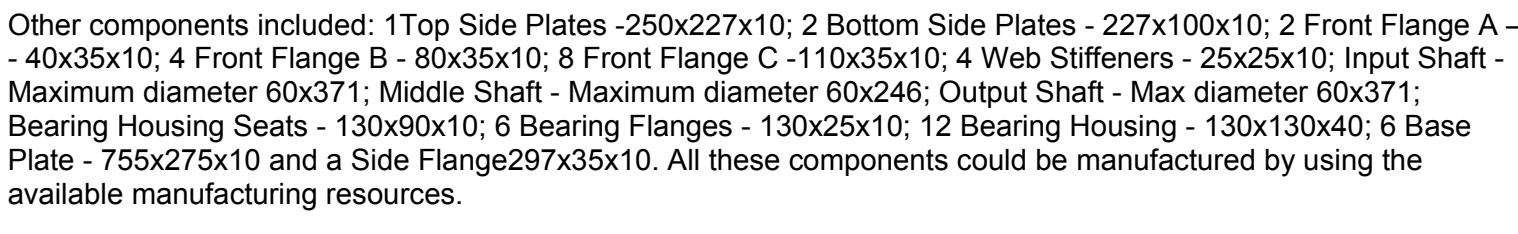 } \\
\hline
\end{tabular}

